\title{
Política de Cotas: Uma democratização ao acesso para cursos de graduação na Universidade Federal de Viçosa ${ }^{1}$
}

\author{
Quota Policy: A democratization of access to undergraduate courses at the \\ Federal University of Viçosa \\ Política de cuotas: em democratización del acceso a los cursos de graduación \\ en la Universidad Federal de Viçosa
}

YKARU GOMES WAGNER https://orcid.org/0000-0002-7900-1617

Universidade Federal de Viçosa

Faculdade de Economia

Departamento de Economia Rural Viçosa, MG, Brasil

LEONARDO CHAVES BORGES CARDOSO https://orcid.org/0000-0001-7544-9070

Universidade Federal de Viçosa

Faculdade de Economia Departamento de Economia Rural Viçosa, MG, Brasil

CRISTIANA TRISTÃO RODRIGUES https://orcid.org/0000-0001-6639-969X Universidade Federal de Viçosa Faculdade de Ciências Econômicas Departamento de Economia Aplicada Viçosa, MG, Brasil

\begin{abstract}
Resumo: Este trabalho visa analisar a política de cotas implementada pela Lei $n^{\circ}$ 12.711/2012 nos cursos de graduação da Universidade Federal de Viçosa, comparando a incidência dos candidatos cotistas aprovados na primeira chamada do Sistema de Seleção Unificada e a incidência desses indivíduos em uma simulação sem o sistema de cotas. A comparação foi auxiliada por meio da estatística qui-quadrado e pelo modelo Logit interpretado pelas razões de chances (Odds Ration). Os resultados mostram que na ausência da política, a incidência de alunos egressos do ensino médio público se reduziria expressivamente.
\end{abstract}

Palavras-chave: Política de Cotas, Simulação, Logit.

1 Este trabalho teve apoio financeiro da Fundação de Amparo à Pesquisa do Estado de Minas Gerais (FAPEMIG). 
Abstract: This work aims to analyze the quotas policy implemented by Law 12.711/2012 in undergraduate courses at the Federal University of Vicosa, comparing the incidence of quota candidates approved in the first call of the Unified Selection System and the incidence of these individuals in a simulation without the quota system. The comparison was aided through chisquare statistics and the Logit model interpreted by Odds Ratios The results show that in the absence of the policy, the incidence of undergraduate students deriving from public high school would be significantly reduced.

Keywords: Quotas Policy, Simulation, Logit.

Resumen: Este trabajo tiene como objetivo analizar la politica de cuotas implementada por la Ley 12.711 / 2012 en los cursos de licenciatura de la Universidad Federal de Viçosa, comparando la incidencia de candidatos a cuotas aprobados en la primera convocatoria del Sistema Unificado de Selección y la incidencia de estos individuos en una simulación sin el sistema de cuotas. La comparación fue asistida por medio de estadísticas de chi-cuadrado y el modelo Logit interpretado por razones de probabilidades (Odds Ration). Los resultados muestran que, en ausencia de la politica, la incidencia de estudiantes que se graduan de la escuela secundaria pública se reduciría significativamente.

Palabras clave: Política de cuotas, Simulación, Logit.

\section{INTRODUÇÃO}

A qualidade do ensino das escolas é de fundamental importância no cenário educacional, social e para o desenvolvimento de um país. Indivíduos que apresentam uma educação básica deficiente não estarão em condições suficientes para concorrer as vagas do ensino superior. Segundo Heringer e Ferreira (2001), historicamente, o Brasil reproduziu e contribuiu com um modelo de educação voltado para a elite brasileira, utilizando processos seletivos que funcionam como filtros em que apenas os mais preparados conseguem ingressar na educação superior pública, perpetuando assim exclusões que prejudicam especialmente populações socialmente mais vulneráveis.

Os efeitos dessas discrepâncias acabam por gerar desigualdades profundas de distribuição de rendas, de forma que, rendas mais altas concentram-se em uma pequena parcela da população e rendas mais baixas concentram na maior parcela da população, o que acaba por aprofundar as desigualdades já existentes (DA SILVA JUNIOR e SAMPAIO 2010). As disparidades nos níveis de escolaridade da população influenciam diretamente nas grandes diferenças de renda, nas desigualdades na remuneração do trabalho e contribuem para reprodução da pobreza (MINCER, 1974). Nesse contexto, a educação é um dos instrumentos capazes de reduzir essas discrepâncias e promover o desenvolvimento social, econômico e cultural de uma nação. $\mathrm{O}$ aumento do nível de escolaridade da 
sociedade, bem como a oferta de um ensino de qualidade nas instituições públicas são desafios a serem perseguidos e solucionados por Governos e pela Sociedade. (FONAPRACE, 2011)

Para Iosif (2007) os problemas no ensino brasileiro começam na educação infantil e vão até o ensino superior, o qual se defronta com questões relacionadas ao acesso, qualidade do ensino e permanência dos estudantes. Diante desse cenário, a vulnerabilidade social, econômica e cultural dos alunos do ensino básico são entraves para o ingresso nos cursos de graduação. Quanto maior a vulnerabilidade, maiores serão as dificuldades enfrentadas para concluir a educação básica e acessar ao ensino superior. Portanto, a educação é um dos indicadores que possibilitariam compreender a desigualdade brasileira e, nesse sentido, ações afirmativas são necessárias para reparar essas assimetrias (FERREIRA, 2000).

As ações afirmativas são políticas compensatórias adotadas para remediar as condições resultantes de um passado de discriminação. Constituem-se como medidas concretas que viabilizam o direito à igualdade e cumprem uma finalidade pública de assegurar a diversidade e a pluralidade social. A discriminação ocorre quando indivíduos são tratados como iguais em situações diferentes, e diferentes em situações iguais (PIOVESAN, 2005). Dessa forma, políticas públicas de ações afirmativas têm como finalidade produzir modificações na disposição da hierarquia social, possibilitando condições aos indivíduos que se encontram em vulnerabilidade de se elevarem socialmente (SOUZA e BRANDALISE, 2012).

Em 2012, com o objetivo de promover a democratização do acesso ao ensino superior, foi implementada uma política pública de ações afirmativas que ficou conhecida nacionalmente como Lei de Cotas Universitárias. A Lei no $12.711 / 2012$ garante a reserva de $50 \%$ das matrículas por curso e turno nas 59 universidades federais e 38 institutos federais de educação, ciência e tecnologia para alunos que cursaram integralmente o ensino médio em escolas públicas nos cursos regulares ou na educação de jovens e adultos. Os demais $50 \%$ das vagas permanecem para ampla concorrência (BRASIL, 2018).

Com intuito de corroborar com a área de políticas públicas voltadas para acesso ao ensino superior, o objetivo do presente trabalho é avaliar se a Lei 12.711/2012 cumpre com o objetivo de democratizar e ampliar o acesso dos alunos que cursaram integralmente o ensino médio na rede pública aos cursos de graduação da UFV.

Especificamente, objetiva-se analisar a lei de cotas, traçando um paralelo, tudo mais permanecendo constante, entre as taxas de aprovação de candidatos cotistas inscritos em primeira chamada no SISU 2017 e a incidência destes indivíduos em um cenário simulado no qual não há reserva de vagas por cotas e o único critério de aprovação é o ranqueamento decrescente das notas do Exame 
Nacional do Ensino Médio (ENEM). Posteriormente, comparou-se os índices de aprovação desses candidatos nos dois cenários (SISU 2017 e o cenário simulado) e, ao final, um modelo Logit foi estimado com o intuito de entender o efeito das variáveis explicativas observáveis nas chances de aprovação dos indivíduos que cursaram integralmente o ensino médio em escolas públicas.

O ano de 2017 foi escolhido por ser o ano mais recente para os dados disponíveis e a Lei $\mathrm{n}^{\circ} 12.711 / 2012$ ter entrado em vigor, em sua totalidade, no ano de 2016.

\section{REFERENCIAL TEÓRICO}

\section{Conceito de políticas públicas}

De acordo com Souza (2006) o estudo de políticas públicas como disciplina acadêmica e área de conhecimento surgiu nos Estados Unidos, rompendo com a tradição europeia que se concentrava na análise do estado e suas instituições. Para Lynn (1980), Política Pública é um conjunto de ações governamentais que produzirão efeitos específicos. Para Rua (2009, p.19), “as políticas públicas são resultantes da atividade política que compreendem o conjunto das decisões e ações relativas à alocação imperativa de valores envolvendo bens públicos".

Políticas públicas envolvem decisões e ações estrategicamente selecionadas para implementação das decisões tomadas. Em suma, é o campo do conhecimento que busca, ao mesmo tempo, "colocar o governo em ação" e, quando necessário, propor mudanças no rumo ou curso dessas ações (RUA, 2009).

\section{Análise, ciclo e avaliação de políticas públicas}

A formulação de políticas públicas constitui-se no estágio em que os governos democráticos traduzem seus propósitos em programas e ações que produzirão resultados ou mudanças no mundo real. O ciclo de políticas públicas é um conjunto de etapas no processo de formulação de uma política, passando por uma formação da agenda, identificação de alternativas, avaliação de opções, seleção das opções, implementação e avaliação da política (SOUZA, 2006).

A Formação da Agenda ocorre quando uma situação é reconhecida como um problema político e a sua discussão integra as atividades de autoridades envolvidas dentro e fora do governo. Posteriormente, a identificação das alternativas, avaliação e tomada de decisão ocorrem quando, após a inclusão do problema na agenda e alguma análise deste, os atores começam a apresentar 
propostas para sua resolução. Essas propostas expressam interesses diversos que necessitam ser combinados de forma alcançar uma solução aceitável para o maior número de partes envolvidas. A implementação é o conjunto de decisões a respeito da operação das rotinas de execução das diversas organizações envolvidas. A política pública é colocada em prática por meio da elaboração e execução dos planos e projetos. Por último, a avaliação, trata da mensuração e análise dos efeitos produzidos pelas políticas. (SOUZA, 2006)

De acordo com Cunha (2006), as avaliações de políticas públicas podem ser classificadas de acordo com vários critérios. Considerando o agente que as realiza, as avaliações podem ser classificadas como avaliação externa, avaliação interna, avaliação mista e avaliação participativa. A avaliação externa é realizada por pessoas de fora da instituição responsável pelo programa que, em geral, possuem experiência neste tipo de atividade. A avaliação interna é realizada com a colaboração das pessoas que participam do programa dentro da instituição responsável. Já a avaliação mista, combina os tipos de avaliação externa e interna, fazendo com que os avaliadores externos tenham contato estreito com os participantes do programa a ser avaliado na tentativa de manter as vantagens e superar as desvantagens das avaliações apresentadas. A avaliação participativa é mais utilizada para pequenos projetos e prevê a participação dos beneficiários das ações no planejamento, na programação, execução e avaliação desses projetos.

Quanto ao momento de sua realização, as avaliações podem ser identificadas como: avaliação ex-ante e avaliação ex-post. A avaliação ex-ante é realizada ao começo de um programa com o intuito de dar suporte à decisão de implementação ou não do programa e ordenar os projetos de acordo com sua eficiência para alcançar os objetivos determinados. A avaliação ex-post é realizada durante a execução de um programa ou ao final, quando as decisões são baseadas nos resultados alcançados. Nesta avaliação, julga-se, quando um programa está em execução, se ele deve continuar ou não e se deve manter a formulação original ou sofrer modificações com base nos resultados obtidos até o momento.

As avaliações ainda podem responder quanto aos tipos de problemas ou perguntas. São elas: avaliação de processo e avaliação de impactos e resultados. A avaliação de processos é realizada durante a implementação de um programa e diz respeito à dimensão de gestão. É uma avaliação que busca detectar problemas ocorridos durante o processo e efetuar correções ou adequações. A avaliação de impactos e resultados tem como objetivo responder se o programa funcionou ou não. Tal avaliação busca verificar em que medida o programa alcança seus objetivos e quais são os seus efeitos após sua implementação. Serve para dar suporte para decisão de continuação do programa e para a formulação de outros (CUNHA, 2006). 


\section{A Lei $\mathrm{n}^{\circ}$ 12.711/2012 (Lei de cotas):}

A Lei $n^{\circ} 12.711 / 2012$, sancionada em agosto de 2012, constitui uma política pública a qual garante a reserva de $50 \%$ das vagas por curso e turno nas 59 universidades federais e 38 institutos federais de educação, ciência e tecnologia, para alunos que cursaram integralmente o ensino médio em escolas públicas em cursos regulares ou na educação de jovens e adultos. Os demais $50 \%$ das vagas permanecem para ampla concorrência (BRASIL, 2012).

As vagas reservadas às cotas (50\% do total de vagas da instituição) serão subdivididas, metade para estudantes de escolas públicas com renda familiar bruta igual ou inferior a 1,5 salários mínimos per capita $(25 \%$ do total de vagas da instituição) e outra metade para estudantes de escolas públicas com renda familiar superior 1,5 salários mínimos per capita ( $25 \%$ do total de vagas da instituição). Dentro dessas divisões, deverão ser reservadas e respeitadas, também, um percentual mínimo, de acordo com o último censo demográfico do Instituto Brasileiro de Geografia e Estatística (IBGE), correspondente a soma de pretos, pardos e indígenas, e pessoas com deficiência física (BRASIL, 2017).

Dessa forma, a lei proporciona a oportunidade de indivíduos semelhantes concorram entre si no Sistema de Seleção Unificada (SISU), utilizando a nota obtida no ENEM dentro das vagas reservadas às características sociais dos participantes.

O SISU é um sistema informatizado, gerenciado pelo Ministério da Educação, pelo qual instituições públicas de educação superior oferecem vagas para os cursos de graduação a candidatos que realizaram a prova do ENEM (BRASIL, 2018).

A Portaria Normativa $n^{\circ} 18 / 2012$, acrescida pela portaria normativa $n^{\circ}$ 9/2017, do Ministério da Educação (MEC), estabelece conceitos básicos para aplicação da lei de cotas, prevê as modalidades das reservas de vagas e as fórmulas para cálculo, fixa as condições para concorrer às vagas reservadas e estabelece a sistemática de preenchimento das vagas reservadas. O critério de cor é auto declaratório, como em toda política de afirmação no Brasil. A renda familiar per capita terá de ser comprovada por documentação (BRASIL, 2017).

A Figura 1 demostra a distribuição das vagas pelo sistema de cotas. 


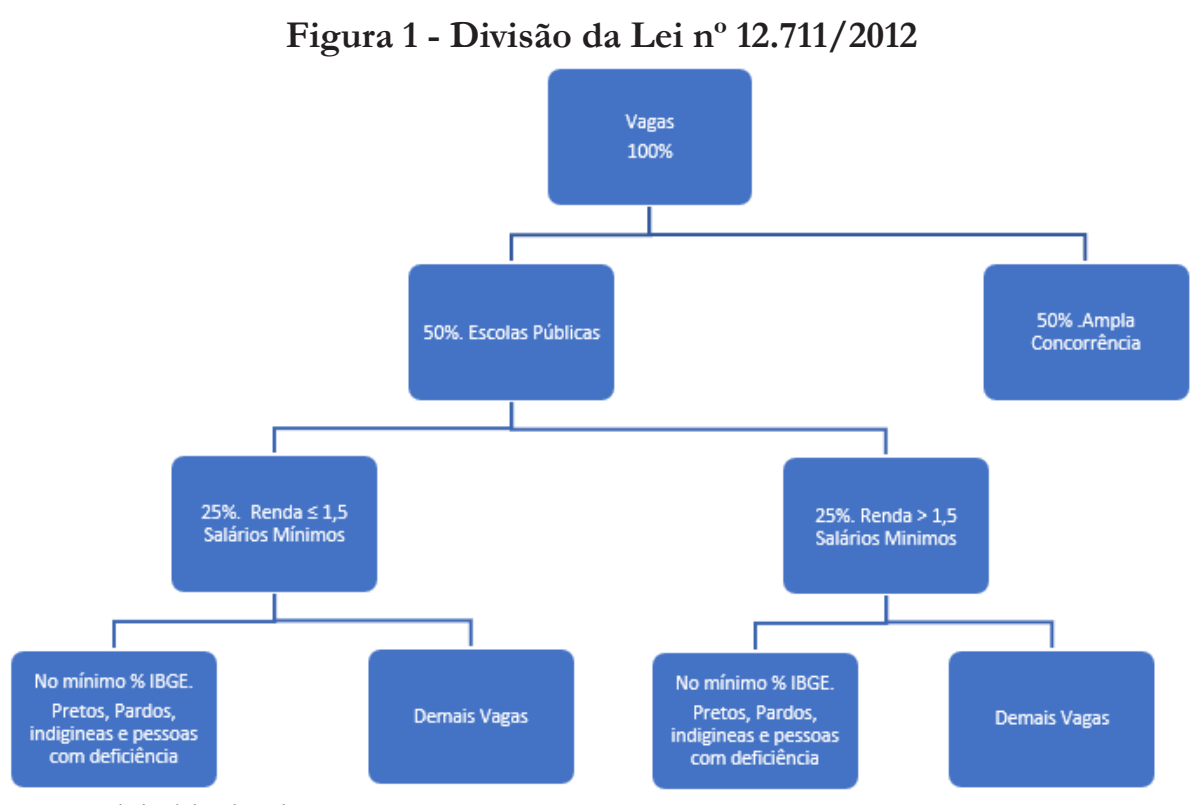

Fonte: Ministério da educação

\section{METODOLOGIA}

\section{Área de estudo e fonte de dados}

Os dados para o estudo foram obtidos por meio de solicitação formal à Pró Reitoria de Educação da Universidade Federal de Viçosa que disponibilizou dados dos inscritos no SISU 2017, Campus Viçosa, para os 41 cursos de graduação da UFV distribuídos entre os centro de Centro de Ciências Agrarias - CCA, Centro de Ciências Biológicas e da Saúde - CCB, Centro de Ciências Exatas e Tecnológicas - CCE, Centro de Ciências Humanas, Letras e Artes - CCH. Os cursos analisados encontram-se no Quadro 2. As informações disponibilizadas de cada candidato foram: nota do ENEM, curso inscrito, aprovação ou reprovação na primeira chamada, data de nascimento, sexo, cidade e estado de domicílio, grupo de ação afirmativa que cada participante concorreu às vagas e número de vagas disponíveis para cada curso. No ano de 2017, o decreto que reserva vagas para deficientes físicos ainda não havia sido assinado. Dessa forma, no período analisado, a reserva de vagas foi dada pelos critérios de natureza da instituição onde o candidato cursou o ensino médio, critérios de renda e critérios de autodeclaração étnico-racial. 
O percentual de vagas destinadas aos candidatos, conforme exige a Lei $\mathrm{n}^{\circ} 12.711 / 2012$ (art. 14, II, Portaria Normativa $\mathrm{n}^{\circ} 18 / 2012$ ) foi de 50\% para ampla concorrência; $11 \%$ para candidatos que, independentemente da renda (renda superior a 1,5 salários mínimos), tenham cursado integralmente o ensino médio em escolas públicas; $14 \%$ para candidatos autodeclarados pretos, pardos ou indígenas que, independentemente da renda (renda superior a 1,5 salários mínimos), tenham cursado integralmente o ensino médio em escolas públicas; $11 \%$ para candidatos com renda familiar bruta per capita igual ou inferior a 1,5 salários mínimos que tenham cursado integralmente o ensino médio em escolas públicas; $14 \%$ para candidatos autodeclarados pretos, pardos ou indígenas, com renda familiar bruta per capita igual ou inferior a 1,5 salários mínimos que tenham cursado integralmente o ensino médio em escolas públicas.

Tais percentuais podem variar em torno de 1\% devido ao número de vagas disponibilizadas por curso onde o percentual se altera pela a impossibilidade de fracionar o número de vagas (exemplo: 40,5 vagas).

As limitações quanto à obtenção dos dados se deram devido à falta de informações de renda e declaração étnico-racial dos candidatos que concorreram às vagas em ampla concorrência (não cotistas). Para tal modalidade não é exigida nenhuma declaração por parte do Ministério da Educação, inviabilizando uma análise mais ampla.

\title{
Quadro 2 - Cursos analisados ${ }^{2}$
}

\author{
Centro de Ciências Agrarias - CCA \\ Agronomia, Cooperativismo, Engenharia agrícola e Ambiental, Engenharia Florestal, Agronegócio, Zootecnia. \\ Centro de Ciências Biológicas e da Saúde - CCB \\ ABI- Ciências Biológicas, Educação Física, Bioquímica, Medicina, Medicina Veterinária, Nutrição, Enfermagem. \\ Centro de Ciências Exatas e Tecnológicas - CCE \\ ABI- Física, ABI- Matemática, ABI- Química, Ciência da Computação, Ciência e Tecnologia de Laticínios, Engenharia mecânica, \\ Engenharia Ambiental, Engenharia de Agrimensura e Cartográfica, Engenharia de Alimentos, Engenharia de Produção, Engenharia \\ Elétrica, Engenharia Química, Engenharia Civil, Arquitetura e Urbanismo. \\ Centro de Ciências Humanas, Letras e Artes $-\mathrm{CCH}$ \\ Administração, Ciências Contábeis, Ciências Econômicas, Comunicação social - Jornalismo, Direito, Educação Infantil, \\ Secretariado Executivo, Serviço Social, ABI- Ciências Sociais, ABI- Dança, ABI- Geografia, ABI- História (HIS), ABI- Letras, \\ Pedagogia.
}

2 Os cursos com a sigla "ABI" à frente do nome, por exemplo: ABI- Ciências Biológicas, são cursos que compreendem as modalidades de licenciatura e bacharelado. 


\section{Simulação}

Para a simulação, construiu-se um cenário simulado, retirando qualquer reserva de vagas no processo seletivo de ingresso aos cursos de graduação da UFV e posteriormente as notas do ENEM dos candidatos inscritos foram ranqueadas de forma decrescente. Assim, respeitando-se o número de vagas ofertadas em cada curso, verificou-se quais candidatos seriam aprovados na inexistência da lei de cotas para cada curso de graduação ${ }^{3}$. Nesse sentido, tudo mais permanecendo constante, a partir da comparação entre número de indivíduos que foram aprovados no SISU 2017 e na simulação (ausência de ações afirmativas), buscouse observar se houve diferenças significativas nos índices de aprovação de cotistas e não cotistas entre os dois cenários, quais grupos de cotistas foram mais afetados e em quais cursos houve maiores diferenças.

Para confirmar se houve diferenças significativas entre os índices de aprovação da situação real e da simulação, foi aplicado o teste de significância não paramétrico qui-quadrado. Em seguida, com objetivo de identificar os efeitos dos fatores étnicos-raciais, renda, sexo e idade, na aprovação dos candidatos cotistas, foram estimadas regressões pelo modelo econométrico Logit e interpretados com auxílio de Odds ratio (razão de chances).

Visando facilitar a compreensão e abreviar as divisões e subdivisões das reservas de vagas estabelecidas pela lei, foram criados grupos conforme descritos abaixo ${ }^{4}$ :

- Ampla concorrência: Grupo 1;

- Candidatos que, independentemente da renda (renda familiar per capita superior a 1,5 salários mínimos) tenham cursado integralmente o ensino médio em escolas públicas: Grupo 2;

- Candidatos autodeclarados pretos, pardos ou indígenas que, independentemente da renda (renda familiar per capita superior a 1,5 salários mínimos) tenham cursado integralmente o ensino médio em escolas públicas (cotistas): Grupo 3;

- Candidatos com renda familiar bruta per capita igual ou inferior a 1,5 salários mínimos e que tenham cursado integralmente o ensino médio em escolas públicas: Grupo 4;

3 Os resultados do trabalho serão apresentados por centro acadêmico devido à inviabilidade de apresentá-los individualmente para cada curso. Dessa forma, o resultado por centro é a soma dos ranqueamentos individuais de cada curso de graduação que os compõe.

4 Candidatos dos Grupos 2,3,4,5 são cotistas e os candidatos do Grupo 1 não são cotistas. 
- Candidatos autodeclarados pretos, pardos ou indígenas, com renda familiar bruta per capita igual ou inferior a 1,5 salários mínimos e que tenham cursado integralmente o ensino médio em escolas públicas: Grupo 5.

A organização dos dados, os cálculos dos testes e a estimação dos modelos foram realizadas utilizando os softwares Excel e Stata.

\section{Teste qui-quadrado}

De acordo com Levin et. al. (2012), o teste qui-quadrado permite testar a significância da diferença entre um conjunto de frequências observadas e um conjunto de frequências esperadas. $\mathrm{O}$ teste pode ser utilizado para determinar se as frequências observadas previamente diferem, de maneira significativa, de uma distribuição uniforme ou qualquer outra distribuição que se possa criar como hipótese. Os desvios observados entre o número de eventos ocorridos e aqueles estimados por determinado padrão são avaliados quanto à sua significância, através de valores tabelados de uma distribuição qui-quadrado (DA SILVA et. al, 2016).

O objetivo do método em questão é comparar se as divergências entre as frequências esperadas e observadas possuem significância estatística. Considerouse como frequência observada a aprovações obtida pela simulação e como frequência esperada a porcentagem de vagas estipulada por lei.

Bruni (2013) diz que para testar se as discrepâncias calculadas possuem significância estatística, calcula-se o índice $X^{2}$ e compara-se com o mesmo fator ( $X^{2}$ crítico) obtido na tabela de distribuição Qui-quadrado.

$O$ índice $X^{2}$ é calculado pela fórmula:

$$
X^{2}=\sum \frac{(O-E)^{2}}{E}
$$

Sendo: $\mathrm{O}=$ Frequência Observada; $\mathrm{E}=$ Frequência Esperada

Cada Grupo de ações afirmativas (Grupo 1, Grupo 2, Grupo 3, Grupo 4, Grupo 5) representa uma observação independente. Sendo assim, o número de graus de liberdade da estatística X 2 é representado pelo número de grupos utilizadas subtraídas por $1(5-1=4)$, devido à característica do teste utilizado. 
Para o trabalho, será utilizado um p-valor com o nível de significância de 99,5\%, correspondendo ao valor de 0,207. O p-valor apresentado pelos testes devem ser menores que o valor apresentado como crítico $(0,207)$ para que haja diferença estatisticamente significativa entre as frequências observadas e as esperadas.

\section{MODELOS ESTIMADOS}

\section{As variáveis utilizadas}

As variáveis explicativas, utilizadas no modelo econométrico e a descrição de suas representações se encontram no Quadro 1.

\section{Quadro 1 - Descrição das variáveis utilizadas}

\begin{tabular}{|l|l|}
\hline \multicolumn{1}{|c|}{ Variável } & \multicolumn{1}{c|}{ Descrição } \\
\hline Aprovação simulação & Assume o valor "1" se o candidato foi aprovado na simulação e "0' caso contrário. \\
\hline $\begin{array}{l}\text { Estudante de escola } \\
\text { pública }\end{array}$ & $\begin{array}{l}\text { Assume valor "1" se o candidato declarou ter cursado integralmente o ensino médio em escola } \\
\text { pública e "0" caso contrário. }\end{array}$ \\
\hline Renda & $\begin{array}{l}\text { Assume valor de "1" se o candidato cotista declara renda familiar per capita inferior a 1,5 salários } \\
\text { mínimos e "0" caso contrário. }\end{array}$ \\
\hline Sexo & Assume valor "1" se o candidato for do sexo feminino e "0" caso contrário. \\
\hline Cor & $\begin{array}{l}\text { Assume valor "1" se o candidato cotista se autodeclara preto, pardo ou indígena e "0" caso } \\
\text { contrário. }\end{array}$ \\
\hline Idade & Idade do candidato na data de inscrição do SISU 2016. \\
\hline Variáveis Região & $\begin{array}{l}\text { Variáveis referentes a cada região geográfica que os candidatos residem foram omitidas do quadro } \\
\text { e representam variáveis de controle. Ao todo somam 5 regiões. O valor "1" representa a região que } \\
\text { o candidato reside e "0" as outras regiões }\end{array}$ \\
\hline Variáveis Grupo & $\begin{array}{l}\text { Variáveis referentes a cada curso que os candidatos se inscreveram foram omitidas do quadro e } \\
\text { representam variáveis de controle. Ao todo somam 5 Grupos de cotistas. O valor "1" representa o } \\
\text { grupo que o candidato se inscreveu e "0" os outros Grupos }\end{array}$ \\
\hline Variáveis Curso & $\begin{array}{l}\text { Variáveis referentes a cada curso que os candidatos se inscreveram foram omitidas do quadro e } \\
\text { representam variáveis de controle. Ao todo somam 42 cursos de graduação. O valor "1" representa } \\
\text { o curso que o candidato se inscreveu e "0" os outros cursos }\end{array}$ \\
\hline Número de observações & \begin{tabular}{l} 
14.781 observaçães. \\
\hline
\end{tabular} \\
\hline
\end{tabular}

Fonte: Elaboração própria

\section{Modelo Logit}

De acordo com Pindyck \& Rubinfeld (1998), o modelo Logit Binomial é um modelo econométrico de seleção qualitativa. O modelo gera respostas de procedimentos qualitativos do tipo presença ou ausência de um determinado atributo. 
Com o objetivo analisar os efeitos das variáveis explicativas na probabilidade dos indivíduos que cursaram integralmente ensino médio em escolas públicas serem aprovados, serão estimadas regressões lineares múltiplas por Máxima Verossimilhança, pelo modelo Logit. A variável dependente será uma dummy que assumirá o valor de "1" caso o indivíduo seja aprovado na seleção e “ 0 ” caso contrário. Por isso, modelos para explicar variáveis dummys são os mais adequados para tal investigação. Dessa forma foi escolhido o modelo Logit para tal análise.

Entretanto, a interação dos resultados do modelo Logit não consideram a magnitude dos coeficientes estimados das variáveis explicativas, dando apenas o sentido da associação (impactos positivos ou negativos). Dessa forma, a utilização das razões de chances (odds ration) se mostram apropriadas para conhecer a magnitude dos coeficientes das variáveis explicativas. A estatística odds ration mostra a interação entre o sucesso, ou seja, a variável dependente assumir valor 1 , em resposta à uma variável independente.

As variáveis explicativas foram elencadas a partir dos requisitos utilizados para a divisão dos grupos dentro da lei de cotas como: ter cursado integralmente o ensino médio em escola pública, renda e autodeclaração étnico-racial. Também foram inseridas na regressão variáveis como idade, sexo, região de domicilio, grupo de cotas e os cursos analisados.

As Equações dos modelos estimados para determinar impacto das variáveis socioeconômicas na chance de aprovação na Simulação:

Aprovacão simulação $=\beta 0+\beta 1 *$ Estudante de Escola Pública $+\beta 2 *$ Sexo $+Z^{\prime} \mu$.

Aprovação simulação $=\beta 0+\beta 1 * \operatorname{Renda}+\beta 2{ }^{*} \operatorname{Cor}+\beta 3 * \operatorname{Sexo}+\beta 4 *$ Idade $+B{ }^{*}$ Estudante de Escola Pública $+Z$ ' $\mu$.

A variável Z' é um conjunto de variáveis dummy e representa a região de domić́lio dos candidatos, o curso que cada candidato se inscreveu e o grupo de cotas que candidato participou no SISU 2017, todas inseridas no modelo como variáveis de controle. Foram realizadas estimações robustas a heterocedasticidade a partir da robustez de white e utilizou-se o teste Count NTR2 para medir o grau de ajuste do modelo.

\section{RESULTADOS}

Nesta seção será apresentada uma análise descritiva, após realizados os testes qui-quadrado, as simulações e os resultados obtidos pelo modelo Logit a partir de três perspectivas: Primeiramente, será apresentado o resultado do teste qui-quadrado. Em seguida, serão comparadas as diferenças percentuais na incidência de cotistas e não cotistas por Centro entre os dois cenários. E, por 
último, serão apresentados os resultados da modelo Logit e as interpretações odds ration, analisando a magnitude das variáveis utilizadas para a divisão das cotas na chance de aprovação dos candidatos cotistas.

\section{Simulação}

Conforme a Tabela $1^{5}$, para o presente trabalho, os Centros analisados (CCA, CCB, CCE, CCH) apresentaram p-valores inferiores ao tabelado $(0,207)$. Portanto tais resultados evidenciam que há diferenças significativas entre as frequências obtidas no quadro de aprovados do SISU 2017 e na simulação na qual o critério para seleção foi apenas o ranqueamento das notas do ENEM. Tais evidencias possibilitam a realização das análises descritas nos objetivos e na metodologia.

\section{Tabela 1 - Teste Qui-quadrado}

\begin{tabular}{|l|l|}
\hline Centro & (P-valor) \\
\hline Centro de Ciências Agrarias - CCA & $6,07 \mathrm{E}-39$ \\
\hline Centro de Ciências Biológicas e da Saúde - CCB & $8,75 \mathrm{E}-44$ \\
\hline Centro de Ciências Exátas e Tecnológicas - CCE & $1,37 \mathrm{E}-65$ \\
\hline Centro de Ciências Humanas, Letras e Artes - CCH & $6,16 \mathrm{E}-45$ \\
\hline P-valor tabelado (99,5\%) & 0,207 \\
\hline
\end{tabular}

Fonte: Elaboração própria.

\section{Análise por Centros}

Nesta seção serão apresentados os resultados a partir da comparação realizada, tudo o mais permanecendo constante, entre o resultado do SISU 2017 e o cenário simulado para cada centro acadêmico.

Conforme apresentado pela Tabela 2, a lei de cotas reservou 235 vagas exclusivas para estudantes que cursaram integralmente o ensino médio em escolas públicas para o Centro de Ciências Agrarias. No entanto, ao analisar a simulação, apenas 99 indivíduos cotistas foram aprovados (21\% do total de vagas), representando uma variação percentual negativa de - $58 \%$ em comparação com a situação real. Os Grupos 3, 4 e 5 foram os mais afetados e apresentaram respectivamente uma incidência de 26, 13 e 7 candidatos aprovados no cenário simulado $(6 \%, 3 \%, 1 \%$ das vagas). Para estes grupos, as variações negativas

5 A notação "E-Númeral", por exemplo: 6,0679E-39, significa que o número é precedido de 39 casas decimais antes da virgula

406 - Rev. Bras. Polít. Adm. Educ. - v. 37, n. 1, p. 394 - 416, jan./abr. 2021 
foram na ordem de $-61 \%,-75 \%,-90 \%$, em relação ao SISU 2017. Tal variação demostra uma redução expressiva de alunos que cursaram integralmente o ensino médio na rede pública. Em contrapartida, para os Grupo 1 e 2 a incidência de aprovados na simulação foi positiva de 79\% (371 vagas) e 11\% (53 vagas) das vagas, concentrando 424 das 470 vagas ofertadas apenas entre esses dois grupos.

Tabela 2 - Resultados descritivos: Centro de Ciências Agrarias: CCA

\begin{tabular}{|c|c|c|c|c|c|c|c|c|}
\hline & Grupo 1 & Grupo 2 & Grupo 3 & Grupo 4 & Grupo 5 & $\begin{array}{c}\text { Total } \\
\text { cotistas }\end{array}$ & $\begin{array}{c}\text { Total não } \\
\text { cotistas }\end{array}$ & Total \\
\hline $\begin{array}{c}\text { Aprovaçã SISU } \\
2017 \text { (A) }\end{array}$ & 235 & 51 & 66 & 51 & 67 & 235 & 235 & 470 \\
\hline $\begin{array}{c}\text { Percentual } \\
\text { candidatos SISU } \\
2017\end{array}$ & $50 \%$ & $11 \%$ & $14 \%$ & $11 \%$ & $14 \%$ & $50 \%$ & $50 \%$ & $100 \%$ \\
\hline $\begin{array}{c}\text { Aprovação simulação } \\
\text { (B) }\end{array}$ & 371 & 53 & 26 & 13 & 7 & 99 & 371 & 470 \\
\hline $\begin{array}{c}\text { Percentual } \\
\text { candidatos simulação }\end{array}$ & $79 \%$ & $11 \%$ & $6 \%$ & $3 \%$ & $1 \%$ & $21 \%$ & $79 \%$ & $100 \%$ \\
\hline $\begin{array}{c}\text { Variação Percentual } \\
\text { (A)-(B) }\end{array}$ & $58 \%$ & $4 \%$ & $-61 \%$ & $-75 \%$ & $-90 \%$ & $-58 \%$ & $58 \%$ & $0 \%$ \\
\hline
\end{tabular}

Fonte: Elaboração própria.

O Centro de Ciências Biológicas e da Saúde foi o centro em que se apresentou a maior diferença entre a simulação e os resultados do SISU 2017. Conforme apresentado na Tabela 3, a Lei 12.711/2012 reservou 372 vagas para cotistas. No entanto, na simulação, apenas 63 estudantes (15\% aprovações) que cursaram integralmente o ensino médio em escolas públicas foram aprovados. Os Grupos 3 e 4 ocuparam, respectivamente, apenas 13 e 15 vagas (7\%) entre os aprovados na simulação. Já os Candidatos que se declararam pretos pardos ou indígenas e com baixa renda (Grupo 5) foram os mais prejudicados na inexistência políticas de ações afirmativas. Para este grupo, a taxa de ocupação foi de apenas 1\% (5 vagas) do total de 410 vagas. Tal incidência corresponde a uma variação percentual negativa de $-92 \%$ entre as aprovações pelo SISU 2017 (60 vagas) e as aprovações desses indivíduos no cenário simulado. Por outro lado, na falta das ações afirmativas, candidatos dos Grupos 1 e 2 , juntos, ocuparam $92 \%$ das vagas (85\% para o Grupo 1 e 7\% Grupo 2). 
Tabela 3 - Resultados descritivos.

Centro de Ciências Biológicas e da Saúde - CCB

\begin{tabular}{|c|c|c|c|c|c|c|c|c|}
\hline & Grupo 1 & Grupo 2 & Grupo 3 & Grupo 4 & Grupo 5 & $\begin{array}{c}\text { Total } \\
\text { cotistas }\end{array}$ & $\begin{array}{c}\text { Total não } \\
\text { cotistas }\end{array}$ & Total \\
\hline $\begin{array}{c}\text { Aprovação SISU } \\
\text { 2017 (A) }\end{array}$ & 205 & 41 & 59 & 45 & 60 & 205 & 205 & 410 \\
\hline $\begin{array}{c}\text { Percentual } \\
\text { candidatos SISU } \\
2017\end{array}$ & $50 \%$ & $10 \%$ & $14 \%$ & $11 \%$ & $15 \%$ & $50 \%$ & $50 \%$ & $100 \%$ \\
\hline $\begin{array}{c}\text { Aprovação simulação } \\
\text { (B) }\end{array}$ & 347 & 30 & 13 & 15 & 5 & 63 & 347 & 410 \\
\hline $\begin{array}{c}\text { Percentual } \\
\text { candidatos simulação }\end{array}$ & $85 \%$ & $7 \%$ & $3 \%$ & $4 \%$ & $1 \%$ & $15 \%$ & $85 \%$ & $100 \%$ \\
\hline $\begin{array}{c}\text { Variação Percentual } \\
\text { (A)-(B) }\end{array}$ & $69 \%$ & $-27 \%$ & $-78 \%$ & $-67 \%$ & $-92 \%$ & $-69 \%$ & $69 \%$ & $0 \%$ \\
\hline
\end{tabular}

Fonte: Elaboração própria.

Para o Centro de Ciências Exatas e Tecnológicas, o percentual de candidatos cotistas no cenário simulado também se reduziu expressivamente. Conforme apresentado na Tabela 4, a taxa de aprovação dos indivíduos que cursaram integralmente o ensino médio em escolas públicas na simulação foi de apenas 21\% (157 indivíduos) contra 372 aprovações reais. Tal diferença representou uma variação percentual negativa de $-58 \%$. Os Grupos 3 e 4 apresentaram uma incidência de 25 e 36 candidatos respectivamente $(3 \%, 5 \%$ vagas); enquanto candidatos do Grupo 5 , novamente, foram os mais afetados, apresentando uma incidência de apenas $1 \%$ entre os aprovados na simulação.

Tabela 4 - Resultados descritivos. Centro de Ciências Exatas e Tecnológicas - CCE

\begin{tabular}{|c|c|c|c|c|c|c|c|c|}
\hline & Grupo1 & Grupo2 & Grupo3 & Grupo4 & Grupo5 & $\begin{array}{c}\text { Total } \\
\text { cotistas }\end{array}$ & $\begin{array}{c}\text { Total não } \\
\text { cotistas }\end{array}$ & Total \\
\hline $\begin{array}{c}\text { Aprovação SISU } \\
2017(\mathrm{~A})\end{array}$ & 372 & 75 & 110 & 76 & 112 & 373 & 372 & 745 \\
\hline $\begin{array}{c}\text { Percentual } \\
\text { candidatos SISU } \\
2017\end{array}$ & $50 \%$ & $10 \%$ & $15 \%$ & $10 \%$ & $15 \%$ & $50 \%$ & $50 \%$ & $100 \%$ \\
\hline $\begin{array}{c}\text { Aprovação simulação } \\
\text { (B) }\end{array}$ & 588 & 87 & 25 & 36 & 9 & 157 & 588 & 745 \\
\hline $\begin{array}{c}\text { Percentual } \\
\text { candidatos simulação }\end{array}$ & $79 \%$ & $12 \%$ & $3 \%$ & $5 \%$ & $1 \%$ & $21 \%$ & $79 \%$ & $100 \%$ \\
\hline $\begin{array}{c}\text { Variação Percentual } \\
\text { (A)-(B) }\end{array}$ & $58 \%$ & $16 \%$ & $-77 \%$ & $-53 \%$ & $-92 \%$ & $-58 \%$ & $58 \%$ & $0 \%$ \\
\hline
\end{tabular}

Fonte: Elaboração própria. 
Já no Centro de Ciências Humanas, Letras e Artes, conforme apresentado na Tabela 5, candidatos que cursaram integralmente o ensino médio em escolas públicas ocuparam $23 \%$ das vagas ofertadas, atingindo apenas 151 aprovações ante as 327 aprovações no SISU. Alunos autodeclarados negros, pardos ou indígenas com renda igual ou inferior à 1,5 salários mínimos (Grupo 5) compuseram 4\% (25 aprovações) contra as 97 aprovações na presença da lei. Já os Grupos 3 e 4 ocupariam 4\% (29 vagas), 5\% (36 vagas) respectivamente entre os aprovados. $\mathrm{Na}$ falta das ações afirmativas, candidatos não cotistas ocupariam 77\% (504 aprovações) das 655 vagas ofertadas, contra as 327 vagas reservadas por lei no SISU 2017. Juntos, os indivíduos dos Grupos 1 e 2 preencheriam 86\% das 655 vagas ofertadas para o Centro de ciências Humanas, Letras e Artes.

\section{Tabela 5 - Resultados descritivos. Centro de \\ Ciências Humanas, Letras e Artes - CCH}

\begin{tabular}{|c|c|c|c|c|c|c|c|c|}
\hline & Grupo 1 & Grupo 2 & Grupo 3 & Grupo 4 & Grupo 5 & $\begin{array}{c}\text { Total } \\
\text { cotistas }\end{array}$ & $\begin{array}{c}\text { Total não } \\
\text { cotistas }\end{array}$ & Total \\
\hline $\begin{array}{c}\text { Aprovação SISU } \\
2017 \text { (A) }\end{array}$ & 327 & 65 & 97 & 69 & 97 & 328 & 327 & 655 \\
\hline $\begin{array}{c}\text { Percentual } \\
\text { candidatos SISU } \\
2017\end{array}$ & $50 \%$ & $10 \%$ & $15 \%$ & $11 \%$ & $15 \%$ & $50 \%$ & $50 \%$ & $100 \%$ \\
\hline $\begin{array}{c}\text { Aprovação simulação } \\
\text { (B) }\end{array}$ & 504 & 61 & 29 & 36 & 25 & 151 & 504 & 655 \\
\hline $\begin{array}{c}\text { Percentual } \\
\text { candidatos simulação }\end{array}$ & $77 \%$ & $9 \%$ & $4 \%$ & $5 \%$ & $4 \%$ & $23 \%$ & $77 \%$ & $100 \%$ \\
\hline $\begin{array}{c}\text { Variação Percentual } \\
\text { (A)-(B) }\end{array}$ & $54 \%$ & $-6 \%$ & $-70 \%$ & $-48 \%$ & $-74 \%$ & $-54 \%$ & $54 \%$ & $0 \%$ \\
\hline
\end{tabular}

Fonte: Elaboração própria.

De forma geral, conforme apresentado na Tabela 6, somando todos os centros analisados, o número de aprovação dos cotistas na simulação foi de 470 aprovações contra 1141 aprovações no SISU, representando uma variação percentual negativa de $-59 \%$. A partir de uma ótica inversa, a presença de ações afirmativas representa um aumento de $142 \%$ de alunos que cursaram integralmente o ensino médio em escolas públicas. Tal resultado evidencia o impacto positivo e abrangente da Lei $n^{\circ}$ 12.711/2012 em promover a inserção de candidatos que cursaram integralmente o ensino médio em escolas públicas, principalmente entre aqueles de baixa renda e autodeclarados pretos, pardos ou indígenas. 
Tabela 6 - Resultados descritivos. Geral- UFV.

\begin{tabular}{|c|c|c|c|c|c|c|c|c|}
\hline & Grupo 1 & Grupo 2 & Grupo 3 & Grupo 4 & Grupo 5 & $\begin{array}{c}\text { Total } \\
\text { cotistas }\end{array}$ & $\begin{array}{c}\text { Total não } \\
\text { cotistas }\end{array}$ & Total \\
\hline $\begin{array}{c}\text { Aprovação SISU } \\
2017(\mathrm{~A})\end{array}$ & 1139 & 232 & 332 & 241 & 336 & 1141 & 1139 & 2280 \\
\hline $\begin{array}{c}\text { Percentual } \\
\text { candidatos SISU } \\
2017\end{array}$ & $50 \%$ & $10 \%$ & $15 \%$ & $11 \%$ & $15 \%$ & $50 \%$ & $50 \%$ & $100 \%$ \\
\hline $\begin{array}{c}\text { Aprovação simulação } \\
\text { (B) }\end{array}$ & 1810 & 231 & 93 & 100 & 46 & 470 & 1810 & 2280 \\
\hline $\begin{array}{c}\text { Percentual } \\
\text { candidatos simulação }\end{array}$ & $79 \%$ & $10 \%$ & $4 \%$ & $4 \%$ & $2 \%$ & $21 \%$ & $79 \%$ & $100 \%$ \\
\hline $\begin{array}{c}\text { Variação Percentual } \\
\text { (A)-(B) }\end{array}$ & $59 \%$ & $0 \%$ & $-72 \%$ & $-59 \%$ & $-86 \%$ & $-59 \%$ & $59 \%$ & $0 \%$ \\
\hline
\end{tabular}

Fonte: Elaboração própria.

Para os candidatos do Grupo 3, o número de aprovados na simulação foi de 93 indivíduos contra as 332 aprovações na presença da lei. O que resulta em uma variação percentual negativa de $-72 \%$ entre os dois cenários. Nesse caso, tomando como base os resultados da simulação, houve um aumento de $256 \%$ de candidatos autodeclarados pretos, pardos ou indígenas que, independentemente da renda, tenham cursado integralmente o ensino médio em escolas públicas.

Em relação ao Grupo 4, a variação percentual entre a simulação e o cenário real foi de $-59 \%$. Neste contexto, apenas 100 candidatos seriam aprovados na inexistência lei de cotas, contra as 241 aprovações dos mesmos candidatos no SISU 2017.

Os Candidatos autodeclarados pretos, pardos ou indígenas, com renda familiar bruta per capita igual ou inferior a 1,5 salários mínimos e que tenham cursado integralmente o ensino médio em escolas públicas, foi o extrato em que a política causou o maior impacto positivo. Para esse grupo, caso na simulação, apenas 46 candidatos seriam aprovados nesse modelo. Tal diferença resultou em uma variação negativa de $-86 \%$ entre os dois cenários. Já na presença da política de ações afirmativas 336 candidatos foram aprovados. Tomando como base os resultados da simulação, a implementação da política, promoveu um aumento de 630\% de indivíduos com tais características. Tal resultado corrobora com o que diz Iosif (2007): quanto maior a vulnerabilidade, maiores serão as dificuldades de ingressar na educação superior caso não existam mecanismos para reduzir essas dificuldades e incluir esses indivíduos.

Os candidatos do Grupo 1, na simulação, preencheram 1810 (79\%) das 2280 vagas disponíveis. Ou seja, na ausência de uma política de ações afirmativas, candidatos que em tese possuem melhores condições socioeconômicas, 
preencheriam quase todas as vagas ofertadas pelos cursos de graduação. Para o Grupo 2, houve a redução de 1 vaga entre o SISU 2017 e a situação simulada. Ou seja, no geral, a política não teve efeito positivo para esse grupo de cotistas.

Dessa forma, os centros mais impactados em ordem crescente foram: Centro de Ciências Humanas, Letras e Artes, Centro de Ciências Exatas e Tecnológicas, Centro de Ciências Agrárias, Centro de Ciências Biológicas e da Saúde. Em relação ao Grupos de cotistas, a política obteve um efeito positivo maior nos Grupo 5, Grupo 4 e Grupo 3, respectivamente.

\section{Resultado do modelo Logit}

Os resultados obtidos utilizando o modelo Logit e as razões de chances (odds ratio) para determinar o impacto dos fatores utilizados para a divisão da lei de cotas na chance de aprovação dos candidatos no cenário simulado estão apresentados nas Tabelas 6 e 7.

Tabela 6 - Coeficientes variáveis explicativas. Probabilidades de ingresso estudantes de escolas públicas na ausência da lei de cotas Logit e Odds Ratio.

\begin{tabular}{|c|c|c|c|c|}
\hline \multicolumn{3}{|c|}{ Logit } & \multicolumn{2}{c|}{ Odds ratio } \\
\hline Variáveis & Coeficiente & Erro Padrão & Coeficiente & Erro Padrão \\
\hline Escola pública & $-1,8860^{* * *}$ & 0,0546 & $0,1516^{* * *}$ & 0,0085 \\
\hline Idade & $-0,1041^{* * *}$ & 0,0105 & $0,9011^{* * *}$ & 0,0095 \\
\hline Sexo & $-0,3183^{* * *}$ & 0,0561 & $0,7273^{* * *}$ & 0,0397 \\
\hline
\end{tabular}

Nota: $* * *$ Significativo a $1 \%$. **Significativo a $5 \% *$ Significativo a $10 \%$ Fonte: Elaboração própria.

Tabela 7 - Coeficientes das variáveis explicativas. Impactos das variáveis socioeconômicas na probabilidade de os cotistas serem aprovados na ausência da lei de cotas- Logit e Odds Ratio.

\begin{tabular}{|c|c|c|c|c|}
\hline \multicolumn{3}{|c|}{ Logit } & \multicolumn{2}{c|}{ Odds ratio } \\
\hline Variáveis & Coeficiente & Erro Padrão & Coeficiente & Erro Padrão \\
\hline Cor & $-1,1947^{* \star *}$ & 0,173 & $0,3027^{* \star *}$ & 0,0523 \\
\hline Renda & $-1,1231^{* * *}$ & 0,1273 & $0,3252^{* \star}$ & 0,0414 \\
\hline Idade & $-0,0693^{* * *}$ & 0,0164 & $0,9330^{\star * *}$ & 0,0153 \\
\hline Sexo & $-0,2084^{*}$ & 0,1064 & $0,8118^{*}$ & 0,0864 \\
\hline
\end{tabular}

Nota: $* * *$ Significativo a $1 \%$. **Significativo a $5 \% *$ Significativo a $10 \%$

Fonte: Elaboração própria. 
Conforme apresentado na Tabela 6, as variáveis Escola Pública, Idade e Sexo apresentaram coeficientes negativos e foram estatisticamente significativas a 1\% pelo modelo Logit. Assim, infere-se que o candidato ter cursado o ensino médio em escola pública, ser do sexo feminino e apresentar idade cada vez mais elevada reduz as chances dele em ingressar nos cursos de graduação UFV no cenário simulado. Pela interpretação Odds ratio, com base no primeiro critério da reserva de vagas, pelo efeito marginal, o candidato ter cursado integralmente o ensino médio em escola pública reduz em $84,86 \%$ as chances de ingressar nos cursos de graduação em comparação a um aluno não cotista. Tal resultado vai ao encontro de Heringer e Ferreira (2001). Na ausência da lei, indivíduos que cursaram integralmente o ensino básico na rede pública não estariam em condições de disputar vagas com aqueles que puderam acessar a educação básica da rede privada.

Dentre os cotistas, conforme apresentado na Tabela 7 , as variáveis cor e idade foram estatisticamente significativas a $1 \%$. A variável sexo foi estatisticamente significativa a $10 \%$. Todas as variáveis em questão também apresentaram sinal negativo, indicando que a presença dessas características é desfavorável nas chances de aprovação dos candidatos, sem a reserva de vagas. Pela interpretação das razões de chances, observa-se que, pelo efeito marginal, o candidato ser autodeclarado negro, pardo ou indígena reduz em 69,73\% as chances de ingressar nos cursos analisados em comparação a um candidato não autodeclarado negro, pardo ou indígena. Já o candidato que apresenta renda familiar per capita igual ou inferior a 1,5 salários mínimos tem suas chances reduzidas em $67,48 \%$, comparado aos candidatos com renda familiar per capita superior a 1,5 salários mínimos. Ou seja, indivíduos que cursaram integralmente o ensino médio em escolas públicas, sobretudo os candidatos de baixa renda e os autodeclarados negros ou indígenas, apresentariam enormes dificuldades para ingressar nos cursos de graduação. Demostrando que, conforme Ferreira (2000), a educação é um indicador que possibilita compreender a desigualdade brasileira e, nesse sentido, ações afirmativas são necessárias para reparar essas assimetrias.

A comparação entre os resultados obtidos na situação simulada e o SISU 2017, bem como os resultados encontrados pelos modelos estimados corroboram com os critérios utilizados para reservar de vagas pela lei. Concatenando a análise proposta pelo modelo apresentado e a análise descritiva, dada a diferença entre as vagas reservadas aos cotistas e a incidência destes na simulação, fica evidente o benefício e o efeito positivo da política pública na inclusão de candidatos mais vulneráveis. Os grupos de ações afirmativas mais beneficiados, foram os grupos de candidatos de baixa renda, especialmente aqueles autodeclarados pretos, pardos ou indígenas. Candidatos esses que compõem a grande parcela da população 
menos favorecida socioeconomicamente e a maior parcela da população brasileira. Caso não houvesse uma política voltada para corrigir essas desigualdades, poucos desses indivíduos teriam acesso ao ensino superior na UFV.

Paradoxalmente com o que se observa na educação básica pública (ensino fundamental e médio) onde está matriculada a maior parte dos estudantes em desvantagens socioeconômicas, as estimativas realizadas mostram que, não havendo ações afirmativas voltadas para a inclusão desses estudantes, apenas uma minoria em melhores condições seria beneficiada com o acesso à educação superior pública, no estudo em questão. A comparação entre a situação real e a simulação, bem como os resultados obtidos pelos modelos estimados, demostram que a política de cotas cumpre com seu objetivo de democratizar o acesso ao ensino superior e comprovam a eficácia da Lei no 12.711/2012 na redução das assimetrias de oportunidades causadas por fatores socioeconômicos.

\section{CONSIDERAÇÕES FINAIS}

Este estudo analisou a eficácia da lei de cotas em cumprir o objetivo de democratizar e ampliar o acesso aos cursos de graduação da Universidade Federal de Viçosa, Campus Viçosa. Para a análise, foi realizada uma comparação, subsidiada pelo teste qui-quadrado, entre a aprovação dos candidatos que concorreram ao SISU 2017 e um cenário simulado em que foram retiradas as reservas de vagas impostas pela lei $\mathrm{n}^{\mathrm{0}} 12.711 / 2012$. Em seguida, foram estimadas regressões com auxílio do modelo Logit e interpretações pelas razões de chances para analisar o impacto dos fatores socioeconômicos utilizados para divisão da reserva de vagas no índice de aprovação dos candidatos cotistas, caso não houvesse ações afirmativas.

Os resultados comprovam que a política implementada causa um impacto positivo e abrangente para a democratização do acesso à UFV. Os critérios utilizados para a separação dos grupos e a reserva de vagas também se mostraram de suma importância para, entre os cotistas, a inclusão daqueles candidatos socioeconomicamente mais vulneráveis. Dessa forma, os grupos de ações afirmativas mais atingidos positivamente foram os grupos de candidatos de baixa renda, especialmente aqueles autodeclarados pretos, pardos ou indígenas.

O presente trabalho evidencia que a política de cotas constitui uma ferramenta de grande importância no auxílio de políticas que buscam inclusão, por meio da educação, a quebra com os ciclos de pobreza e ascensão social das classes menos favorecidas. Todavia, de forma isolada, tal ação será apenas um meio reparador e muitas vezes, não eficaz, de sanar as desigualdades existentes 
entre os ensinos básicos privado e público, haja vista que, o ensino básico é de fundamental importância como ferramenta promotora de alfabetização, emancipação social, cidadania e civilidade.

Vale ressaltar que apesar do cenário simulado fornecer magnitudes imperfeitas, visto que as escolhas dos candidatos deveriam ser mantidas entre a situação real e a situação em que não há ações afirmativas, diante da análise, é possível considerar o efeito positivo da lei de cotas na inserção de alunos de escolas públicas e a democratização do acesso aos cursos de graduação. A ausência de variáveis capazes de ampliar o poder de explicação dos modelos apresentados é um fator limitante do trabalho. Assim, sugere-se estudos posteriores que consideram outras variáveis, bem como o impacto de políticas de ações afirmativas sobre outros fatores e com outras metodologias.

\section{REFERENNCIAS}

BRASIL. Lei $\mathbf{n}^{\circ} \mathbf{1 2 . 7 1 1}$, de 29 de agosto de 2012, que dispõe sobre o ingresso nas universidades federais e nas instituições federais de ensino técnico de nível médio e dá outras providências.

BRASIL. Lei $\mathrm{n}^{\mathbf{0}}$ 13.409, DE 28 DE DEZEMBRO DE 2016, altera a Lei no 12.711, de 29 de agosto de 2012, para dispor sobre a reserva de vagas para pessoas com deficiência nos cursos técnico de nível médio e superior das instituições federais de ensino.

BRASIL. Ministério da Educação. Disponível em < portal.mec.gov.br>. Acesso em: 17 de outubro de 2018.

BRASIL. Decreto $\mathbf{n}^{\circ} \mathbf{7 . 8 2 4}$, de 11 de outubro de 2012 (regulamenta a Lei 12.711/2012).

BRASIL. DECRETO $\mathbf{n}^{\mathbf{0}} \mathbf{9 . 0 3 4}$, DE 20 DE ABRIL DE 2017.

BRUNI, A. L. Estatística aplicada à gestão empresarial. Editora Atlas SA, 2013.

CUNHA, C. G. S. DA. Avaliação de Políticas Públicas e Programas Governamentais: tendências recentes e experiências no Brasil. Secretaria de Coordenação e Planejamento/RS, 2006. 
DA SILVA GREGORIO, T, F; DOS SANTOS, R. C. E; MARTINS, E. R. Cálculo atuarial de projeção de receitas e custos das pensões dos militares das forças armadas do Brasil. Blucher Marine Engineering Proceedings, v. 2, n. 1, p. 896-909, 2016.

DA SILVA JÚNIOR, L. H.; SAMPAIO, Y. Notas sobre pobreza e educação no Brasil. Problemas del desarrollo, v. 41, n. 163, p. 75-97, 2010.

FERREIRA, F. H. G. Os determinantes da desigualdade de renda no Brasil: luta de classe ou heterogeneidade educacional? Texto para Discussão, n. 415, fev. $/ 2000$.

FONAPRACE - Fórum Nacional de Pró-Reitores de Assuntos Comunitários

e Estudantis. Perfil Socioeconômico e Cultural dos Estudantes de Graduação das Universidades Federais Brasileiras. Brasília, 2011.

HERINGER, R.; FERREIRA, R. Análise das principais políticas de inclusão de Estudantes negros no ensino superior no Brasil no período 2001 - 2008. In: PAULA, M. de; HERINGER, R. (Orgs.) Caminhos convergentes - Estado e sociedade na superação das desigualdades raciais no Brasil. Rio de Janeiro: Fundação Heinrich Boll, ActionAid, 2009, p. 137-162.

IOSIF, R. M. G. A qualidade da educação na escola pública e o comprometimento da cidadania global emancipada: implicações para a situação da pobreza e desigualdade no Brasil. 2007. 310f. Tese (Doutorado em Política Social), Universidade de Brasília, Brasília, 2007.

LEVIN, J; FOX, J. A; FORDE, D. R. Estatística para Ciências Humanas. 11 ${ }^{\mathrm{a}}$ ed. São Paulo: Pearson Education do Brasil, 2012.

LYNN, L. E. Designing Public Policy: A Casebook on the Role of Policy Analysis. Santa Monica, Calif.: Goodyear. 1980

MEAD, L. M. Public policy: vision, potential, limits. Policy Currents, v. 5, p. $1-4,1995$.

MINCER, J. Schooling, experience, and earnings. New York: National Bureau of Economic Research: Columbia University, 1974. 
PIOVESAN, F. Ações Afirmativas sob a perspectiva dos Direitos Humanos. In: SANTOS, S. A. dos. (Org.). Ações afirmativas e combate ao racismo nas Américas. Brasília: Ministério da Educação, Secretaria de Educação Continuada Alfabetização e Diversidade. 2005.

RUA, M. DAS G. Políticas públicas. Florianópolis: Departamento de Ciências da Administração/UFSC, 2009.

SOUZA, A. C.; BRANDIALISE, M. A. T. A política de cotas da UEPG: Da implantação à implementação de uma política pública. In: IX ANPED Sul. Anais: Caxias do Sul. 2012.

SOUZA, C. Políticas Públicas: uma revisão da literatura. Sociologias, Porto Alegre, ano 8, no 16, jul/dez 2006, p. 20-45, 2006

\section{Ykaru Gomes Wagner}

Graduado em Administração pela Universidade Federal de Viçosa (2017). Mestre em Economia Aplicada pela Universidade Federal de Viçosa em (2020). Interessado por temas relacionados à Políticas Públicas Educacionais e Ciências Agrárias. E-mail: ykarugw@yahoo.com.br

\section{Leonardo Chaves Borges Cardoso}

Graduado em Ciências Econômicas (2009) pela Universidade Federal da Bahia. Mestre (2012) e Doutor em Desenvolvimento Econômico (2016) pela Universidade Federal do Paraná. Atualmente é Professor Adjunto no Departamento de Economia Rural da Universidade Federal de Viçosa DER/ UFV. E-mail: leonardocardoso@ufv.br

\section{Cristiana Tristão Rodrigues}

Graduada em Ciências econômicas (2007), Mestre (2010) e Doutora em Economia Aplicada (2014) pela Universidade Federal de Viçosa, com período de sanduíche na University of Califórnia, Riverside (2012). Atualmente é professora do Departamento de Economia na Universidade Federal de Viçosa. E-mail: cristiana.rodrigues@ufv.br 